\title{
Маленький человек в неевклидовом мире: о художественном пространстве в фильме и пьесе Т. Стоппарда "Розенкранц и Гильденстерн мертвы"
}

\author{
Олег Борисович Заславский \\ Department of Mechanics and Mathematics, \\ Kharkov V. N. Karazin National University \\ Svoboda Square 4, Kharkov 61077, The Ukraine \\ e-mail: ozaslav@kharkov.ua
}

\begin{abstract}
Oleg B. Zaslavskii. The little in a non-Euclidean world: On the artistic space in Tom Stoppard's film and play "Rosencrantz and Guildenstern are dead". It is shown that quite different aspects of Tom Stoppard's work - spatial organization, relationship between reality and the conditional character of events, causality and narrative links, the problems of choice and personality - are united by the spatial one-sided model like the Möbius strip or Klein bottle. The artistic space turns out to be not orientable, the time being cyclic. This enables us to explain the mutual exchange of names between Rosencrantz and Guildenstern and a number of other paradoxical features in the plot and composition. The model like the Möbius strip embodies the absence of a free choice: there is no other side in the world and there is no chance to escape from the fate indicated in the title of Tom Stoppard's work. The relevance of topology, e.g. the property of a global nature, is connected with the fact that a bearer of danger is the world as a whole. Apart from this, it points to the fact that such a structure of the world is essentially "non-Euclidean" and cannot be understood on the basis of observations from every-day life or "obvious" experiments like those carried out by Rosencrantz.
\end{abstract}

\section{Введение}

В настоящее время драматургия Стоппарда является объектом изучения с самых разных точек зрения, и о ней имеется обширная литература (примерами могут служить недавние монографии 
Fleming 2001, Bloom 2003). Между тем, есть важный аспект, который до сих пор был лишь бегло затронут в исследованиях. Речь идет о пересечении художественного мира Стоппарда с миром науки, главным образом математики и физики. Например, в "Аркадии" содержится в свернутом виде обсуждение идей, связанных с фракталами, хаосом и вторым началом термодинамики (Jackson 1995; Peterson 2002). В произведении "Professional foul" значимы понятия теории катастроф (Cobley 1984). В пьесе "Hapgood" имеются интересные соответствия между свойствами сюжета и такими особенностями квантовой механики как влияние измерения на результат эксперимента, невозможность точной локализации объекта, квантовые скачки и т.д. (Brouwer 1994: Sec. VI). В данном отношении пьесе "Розенкранц и Гильденстерн мертвы” повезло меньше. Обычно рассмотрение роли математики ограничивается здесь обсуждением диалога двух героев о теории вероятности. Характерно, что на сайте "Mathematical Fiction", специально посвященном отражению математики в художественной литературе и театре, эта пьеса включена в список лишь под нажимом читателей. ${ }^{1}$ В одноименном фильме Стоппарда сциентистский аспект усилен тем, что Розенкранц по ходу действия неоднократно ставит физические опыты. Между тем, роль научных идей в художественном произведении отнюдь не исчерпывается их явным обсуждением непосредственно в тексте или демонстрацией опытов. Наибольший интерес здесь представляет случай, когда соответствующие абстрактные конструкты (которые могут быть вообще не эксплицированы в тексте) организуют саму художественную структуру произведения. Именно такому явлению и посвящена данная работа.

\footnotetext{
1 "This brilliant, weird play, retelling the story of Shakespeare's Hamlet from the point of view of two "throw away" characters, unfortunately has very little mathematics in it. However, every few days I get an e-mail message from someone suggesting that I add it to the list, so I will" (http://www.math.cofc.edu/ faculty/kasman/MATHFICT/mfview.php?callnumber=mf129).
} 


\section{Безальтернативное пространство}

Речь пойдет об одной, но ключевой особенности языка пространственных отношений в произведении Т. Стоппарда "Розенкранц и Гильденстерн мертвы”. Она является общей для обоих художественных произведений - пьесы и фильма, ${ }^{2}$ но поскольку в фильме как тексте иконической природы она проявляет себя более наглядно, мы в основном (делая необходимые оговорки) сосредоточимся на фильме.

В представленном там мире с самого начала действует странность: подброшенная монета неизменно падает одной и той же стороной. При этом выпадает “орел” — по-английски "heads”, так что Гильденстерн говорит даже о "double-headed coins" — это довольно очевидным образом намекает на мотив казни (в фильме повешения), причем две головы орла соответствуют двум головам незадачливых героев (этот момент пропадает при переводе с английского на русский). Не в силах понять, почему же монета падает лишь одной стороной, Гильденстерн однако воспринимает это как намек на нечто угрожающее. В фильме он спрашивает Розенкранца, не испытывает ли тот страх (“No fear?”); в пьесе он говорит: “И это все? И никакого страха? [...] Да, страха! Такая, знаешь, щелка, сквозь которую мозги заливает светом!” (Здесь и далее мы используем перевод И. Бродского - Стоппард 2000.) Судя по трагическому финалу, интуиция не обманула героя в том, что касается “страха". Это заставляет с особенным вниманием отнестись и к его словам о том неясном и пугающем, что стоит за опытами с монетой: как мы сейчас увидим, в этих опытах действительно проступает фундаментальная характеристика мира произведения в целом. Она связана с нейтрализацией противоположностей и дискредитацией выбора.

Это, прежде всего, относится к проблеме индивидуальности. По ходу дела время от времени оказывается невозможно разобрать, кто из героев есть кто - причем их имена путают как другие действующие лица, так и они сами, так что различие между Розенкранцем и Гильденстерном ставится под сомнение. Приведем сначала пример первого рода. "Гамлет. Мои милейшие друзья! Как поживаешь, Гильденстерн? (Идет к авансцене с

2 Rosencrantz and Guildenstern are Dead. Режиссер Том Стоппард, сценарий Тома Стоппарда. Metro Goldwyn Mayer, 1990. 
рукой, протянутой к Розенкранцу, Гильденстерн кланяется. Гамлет поправляет себя.) Ах, Розенкранц!” В дальнейшем Гамлет повторяет эту ошибку (начало 2-го действия): “Гамлет (к Розенкранцу). Слушайте, Гильденстерн, и ты (к Гильденстерну), Розенкранц". Пример второго рода: "Розенкранц. Мое имя Гильденстерн, а это - Розенкранц. Гильденстерн делает ему замечание. (Без смущения.) Виноват, его имя Гильденстерн, а Розенкранц - это я". ${ }^{3}$ В ходе игры в вопросы и ответы (перед первой встречей с Гамлетом) герои, пытаясь подготовиться к этой встрече, лишь воспроизводят указанную путаницу. Гильденстерн обращается к Розенкранцу: “Гильденстерн!”, и тот откликается. В свою очередь, Розенкранц, сбитый с толку предшествующей репликой Гильденстерна, обращается к нему: “Мой милый Розенкранц!”. Характерен вопрос в ходе этой игры: “А я в таком случае должен стать тобой?".

По всему произведению рассыпаны намеки на то, что неотчуждаемые признаки человека потеряли свою устойчивость и способны к превращениям и взаимным перераспределениям между разными людьми, так что в этом мире понятие личности теряет однозначность. Так, в пьесе во время нападения пиратов Розенкранц, Гильденстерн и Актер спасаются, прыгая в бочки. Однако потом Розенкранц и Гильденстерн вылезают из бочки Актера, Актер - из бочки Гамлета (Гамлет же исчезает) 一 как если бы произошло превращение в самом буквальном смысле. Другой пример. В фильме показан издали персонаж, напоминающий фигурой и длинными волосами женщину, полуодетый в женское платье; лишь когда персонаж оборачиваются, он оказывается мужчиной (сцена в бане). Это выглядит так, будто бы женщина превратилась в мужчину, так что пол обнаружил способность к превращениям.

Аналогичным образом обстоит дело и с соотношением персонажа и его ролей. В фильме актер, игравший в таверне убитого Полония, играет в сцене пантомимы во дворце Луциана. Сам же Луциан из персонажа, соответствующего в "Гамлете" убийце Клавдию, превращается в фильме в персонаж, функционально эквивалентный Гамлету. В пьесе в пантомиме, разыгрываемой актерами, “убитый король играет Полония" (“the murdered king to

3 Здесь и далее, отсутствие уточнений источника цитаты (фильм или пьеса) означает, что фраза вошла и в фильм и в пьесу. 
stand in for Polonius") - происходит как бы превращение одного персонажа в другой. Более того, сама фраза построена таким образом, что можно подумать, будто к тому же произошло и буквальное смешение персонажей и актеров, так что Полония и в самом деле играет убитый король, а не актер, который его играл. Когда же согласно действию этой пантомимы, описанному в пьесе, корабль прибывает в Англию, “перемена головного убора превращает актера, игравшего только что убитого короля, в английского короля". В пьесе Розенкранц рассказывает анекдот, в котором представители трех религий (христианин, мусульманин и иудей) обмениваются религиозной принадлежностью и именами, создавая немыслимые в реальном мире сочетания. В другом анекдоте речь идет о том, что христианин на небе встречает Савла, который сообщает, что он уже Павел. В таком контексте по-особому звучат слова Гамлета “дядя-отец”, “мать-тетя", указывающие на то, что неоднозначность затрагивает и родственные отношения. Сказанное относится не только к свойствам человека и личности, но к целому ряду пар контрастных состояний - условность-реальность, явь-сон и т.п.: они не разделены однозначно, а взаимно превращаемы. Например, это проявляет себя в пьесе в притче о философе и бабочке: "Один китаеза, из династии Тан, - по мнению некоторых, большой философ, - ему однажды приснилось, что он — бабочка, и с этой минуты он уже никогда не был полностью уверен, что он не бабочка, которой снится, что она китайский философ...". Устранение контраста между противоположностями проявляет себя и в интертекстуальном взаимодействии. В фильме присутствует цитата из "Blow up" Антониони - площадка для игры в теннис, на которой сама игра заменена условным действом. В фильме Антониони это была игра воображаемым мячом, в фильме Стоппарда - игра в вопросы и ответы. Однако если у Антониони воображение и реальность сохраняли смысл как противоположные в норме категории (и именно поэтому нарушение нормы становилось значимым), то в произведении Стоппарда упразднение границы между противоположностями и разными семиотическими уровнями из аномалии стало нормой. В частности, в данной сцене стерта грань между вопросами и утверждениями, между фразами, входящими в игру, и описанием ее правил (т.е. текстом и метатекстом); это находит и наглядное 
соответствие - в упомянутой выше сцене сетка на поле, маркирующая границу между противоположными сторонами, приспущена.

Все эти особенности получают простое истолкование на языке пространственных отношений, если допустить, что художественный мир произведения в том, что касается любых альтернатив, устроен как лист Мебиуса, т. е. является односторонней поверхностью ${ }^{4}$. Подчеркнем, что речь идет не о физическом пространстве, а об абстрактном - пространстве выбора. В этом случае сразу же становится понятным, почему монета выпадает только одной стороной: хотя в обычном физическом пространстве у нее есть две стороны (орел и решка), в пространстве альтернатив - только одна. (Как говорит Гильденстерн, "По крайней мере, у нас есть варианты. [...] Хотя нет выбора".)

Важное свойство листа Мебиуса (рис. 1 и 2) состоит в том, что он является неориентируемой поверхностью. Если, двигаясь по замкнутому контуру вдоль ее края, обносить перпендикуляр к ней, то по возвращении в исходную точку он окажется направленным по отношению к исходному направлению в противоположную сторону. Указанное свойство художественного пространства фильма позволяет просто описать на таком языке

4 Замкнутым вариантом односторонней поверхности является бутылка Клейна, однако для определенности мы будем в основном говорить о листе Мебиуса. Сама по себе актуальность в произведении поверхности такого типа достаточно очевидна из-за явного упоминания одностороннего выпадения монеты - в этом отношении мы не претендуем на новизну наблюдения. Цель настоящей статьи другая - проследить, как указанное свойство проявляет себя в художественной структуре произведения в целом.

Известная нам попытка связать произведение Стоппарда с топологически нетривиальными структурами является неудачной. Caris (1987: Ch. 6) утверждает: "Tom Stoppard makes a Klein bottle transformation in William Shakespeare's Hamlet". Основанием для этого автор считает тот факт, что актеры представляют на сцене события не только прошлого, но и будущего. Однако такое "знание будущего" (встречающееся например в "научно"фантастической литературе вне всякой связи с бутылкой Клейна) само по себе еще не обязательно означает цикличность времени. Кроме того, даже в случае квазициклических условий возможны разные топологии (как это ясно при склеивании полоски в цилиндр или лист Мебиуса). В применении же к линии (в данном случае линии времени), т.е. одномерному объекту, вообще нет смысла говорить о бутылке Клейна, которая является двумерным объектом. 
неоднократно происходящее “превращение” Розенкранца в Гильденстерна и наоборот. Розенкранц и Гильденстерн в таком контексте предстают как две “точки”, задающие “вектор”, однако в результате “обхода по замкнутому контуру” (обращения героев друг к другу, их взаимных вопросов - ответов, реплик и т.д.) ориентация этого вектора меняется на противоположную, так что Розенкранц превращается в Гильденстерна, а тот - в Розенкранца (ср. высказанное в пьесе опасение Гильденстерна: "Не то будем тут кружить всю ночь, наступая друг другу на пятки”). Неслучайно герои Стоппарда столь озабочены проблемами своей ориентации, причем это выражено как раз в терминах стрелок и компасов: из-за одностороннего характера листа Мебиуса ориентация на нем имеет только локальный, но не глобальный смысл, и может измениться в результате обхода. Как говорит в пьесе Гильденстерн, “Здесь на компас надеяться не приходится”. Иначе говоря, пара Розенкранц - Гильденстерн представляет собой своего рода единый объект, определенный на односторонней поверхности, а не совокупность двух самостоятельных. В пьесе Гильденстерн заявляет “[...] я не в силах считать нас самих чемлибо большим, чем парой золотых с орлом и решкой”, но монета оказывается на самом деле односторонней, и то же относится и к паре этих персонажей - разделение на две самостоятельных личности иллюзорно.
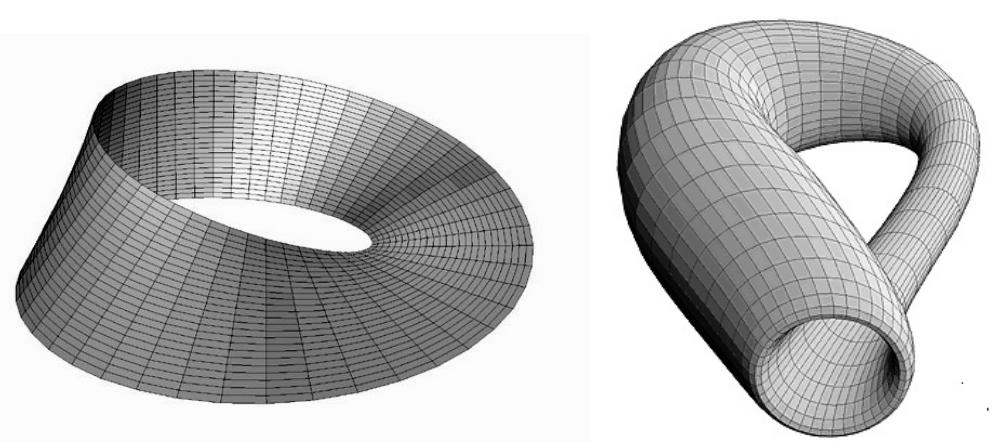

Puc. 1. Лист Мебиуса и бутылка Клейна. 


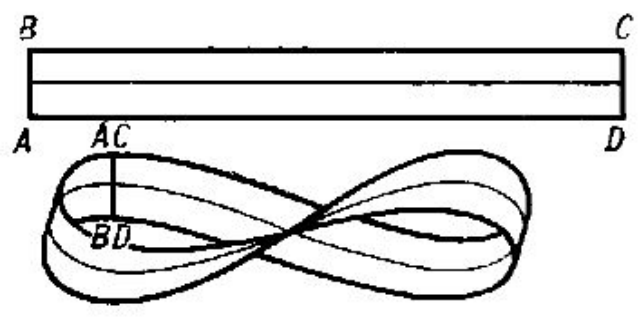

Puc. 2. Лист Мебиуса может быть получен двух противоположных сторон $\mathrm{AB}$ и $\mathrm{CD}$ прямоугольника $\mathrm{ABCD}$ так, что точки А и В совмещаются соответственно с точками $\mathrm{C}$ и $\mathrm{D}$.

Приведем еще ряд примеров подобного рода. Розенкранц вытирает яблоко о камзол Гильденстерна, а тот его благодарит очевидно считая, что Розенкранц хотел вытереть не яблоко, а камзол товарища. Здесь сочетание “очищаемая сторона - яблоко, чистящая сторона - камзол” (точка зрения Розенкранца), поступив к Гильденстерну и отразившись его репликой к Розенкранцу, заменилась на "очищаемая сторона - камзол, чистящая сторона - яблоко": произошло как бы перекручивание, характерное для листа Мебиуса. (Как известно, эта поверхность может быть получена, если взять обычную полоску бумаги и отождествить концы не так, как это происходит при склеивании в цилиндр, а крест-накрест.) Причем актуальность здесь именно пространственной модели усилена тем, что “перекручивание" относится как раз к свойствам геометрической поверхности соприкасающимся сторонам яблока и камзола (наглядный пример перекручивания - состояние теннисной сетки в предшествующей сцене игры в вопросы и ответы, о которой говорилось выше).

Во дворце незадолго до выступления актеров Гильденстерн замечает заслонку в стене, резко ее отодвигает, сразу захлопывает, а потом вновь ее открывает. Оказывается, что с внутренней стороны дверца зеркальна, и перед этим зеркалом актер в маске совершает последние приготовления перед выступлением. При этом существенно, что точка зрения, с которой показана сцена, меняется по ее ходу. Сначала камера показывает происходящее с точки зрения Гильденстерна, так что перед зрителем до захлопывания дверцы быстро мелькает лицо в маске, возникшее в пустом 
проеме, потом сцена дана со стороны актера, так что зритель вместе с ним видит лицо в маске, отразившееся в зеркале. Само по себе зеркало здесь как физический объект ничем не примечательно: это обычная двусторонняя поверхность, у которой только одна сторона покрыта отражающим материалом. Однако в контексте данной сцены такая подвижная заслонка функционально проявила себя как “одностороннее зеркало": с какой стороны ни посмотреть в него, оно показывает зазеркального двойника, причем одного и того же. Более того, этим двойником оказалось лицо в маске - в полном соответствии со сказанным выше о связи между односторонней поверхностью и стиранием индивидуальности. Заметим еще, что когда Розенкранц в этой сцене отвлекает Гильденстерна, показывая ему бумажный самолетик необычной двойной конструкции, тот в раздражении его сплющивает, т.е. проделывает по отношению к самолетику ту же операцию превращения двойного в одинарное, которая происходит в этой сцене и по отношению к зеркалу.

У Стоппарда Розенкранц и Гильденстерн распечатали письмо к английскому королю, узнали, что везут Гамлета на гибель, и запечатали обратно; Гамлет же подменил это письмо другим - с просьбой казнить Розенкранца и Гильденстерна. В данном контексте знаменательно, что этой подмене в фильме предшествует эпизод, когда Гильденстерн запечатывает письмо монетой, т.е. “односторонним” в контексте фильме объектом: непреложная гибель персонажей письма (“односторонняя” ситуация) сочетается с изменением индивидуальности казнимого - Розенкранц и Гильденстерн в результате проделанных Гамлетом операций с текстом как бы превращаются в Гамлета, о казни которого была просьба в первоначальном тексте. Это находит и более наглядное воплощение в фильме: когда Розенкранц и Гильденстерн обнаруживают, что Гамлет попал на корабль пиратов, и таким образом их миссия провалилась, то чтобы обезопасить себя перед английским королем, Розенкранц (забывая вначале, о чем датский король просил английского в своем письме) предлагает себя или своего друга выдать за Гамлета. В данном контексте приобретает смысл и тот факт, что перемена объекта казни происходит в результате манипуляций с куском бумаги - т.е. объектом, при помощи которого лист Мебиуса и может быть реализован наглядным образом. 
В том или ином виде замкнутый контур представлен в фильме и непосредственно, будучи связан с мотивом смерти. Розенкранц делает из бумаги и запускает “самолетик”, который, скрывшись из кадра и описав петлю, возвращается, причем как в момент запуска, так и в момент возвращения между Розенкранцем и Гильденстерном шел разговор о неминуемости смерти. В конце показаны кольца веревки, на которой вешают героев. Пространственная модель с движением по (квази)замкнутой линии, приводящая в результате полного цикла не к точному возвращению в исходную точку, а к “перевороту” или "сдвигу”, организует и собственно временные характеристики. С одной стороны, есть текст с инвариантным сюжетом о гибели: Актер подчеркивает, что при приближении к финалу “все, кому назначено умереть, умирают" - “Это написано”, а также вспоминает: “Я бывал здесь и раньше" - в данном контексте "раньше" можно понимать как относящееся к одному из предыдущих воплощений “Гамлета", включая собственно шекспировский "Гамлет". Иначе говоря, разыгрываемый перед зрителями сюжет - всего лишь один цикл нескончаемого процесса. После раскрытия театрального сундука разыгрывается вариант "Гамлета"; потом он заканчивается, актеры складывают сундук и путешествуют дальше до новых представлений. С другой стороны, сам текст не является строго однозначным и допускает “флуктуации”, свидетельством чему является хотя бы то обстоятельство, что сюжет фильма (в промежутке между тем, как актеры устанавливают сцену и убирают декорации обратно в сундук) представляет собой не в точности "Гамлет", а его вариацию. Как говорит Гильденстерн в конце, “Ладно, в следующий раз будем умнее”: сюжет предстает не как окончательный и завершенный, а всего лишь как один из витков нескончаемой и повторяемой истории, в новом цикле которой героям (согласно этому замечанию Гильденстерна) возможно удастся избежать казни. Поскольку, однако, в данном контексте сама пьеса (фильм) Стоппарда оказывается как раз одним таким “следующим разом" по отношению к "Гамлету", то это свидетельствует о необоснованности упомянутой Гильденстерном альтернативы: герои не стали "умнее" и вновь гибнут, чем подрывается и надежда на “следующий раз” на новом витке истории, но все по той же односторонней 
поверхности. ${ }^{5}$ Столь тревожившая героев проблема выпадения орла или решки при бросании монеты (“heads - tail”, “голова хвост”) получает теперь неожиданное решение: накинутые на шеи героев длинные веревки представляют собой не что иное, как вариант того же сочетания "голова - хвост", причем казнь знаменует собой завершение, конец (еще одно значение слова "tail”) показанного витка истории героев. При этом объединение в образе висельника “головы” и “хвоста", отвечающих двум различным, казалось бы, сторонам монеты (орлу и решке), само по себе отсылает в данном контексте к листу Мебиуса.

Циклический характер сюжета позволяет объяснить и два парадокса - почему в таверне в сцене пантомимы показаны не прошлые, а будущие события, включая казнь Розенкранца и Гильденстерна, и почему во время представления во дворце король-персонаж встает раньше, чем это делает "настоящий" король. Объяснение состоит в том, что на предыдущих витках сюжета все то, что показано на сцене во вставном представлении, "уже было" - и казнь героев, и вставание разгневанного короля во время представления, так что актеры воспроизводят не однократные события из недавнего прошлого (как это было в "Гамлете"), а инвариантный повторяющийся сюжет. Тем самым соответствующие события на сцене приобретают двойной статус в пределах цикла, который видит зритель фильма, они изображают будущее, но с учетом предшествующих циклов пантомима (как и вставное представление в “Гамлете") раскрывает прошлое $^{6}$. Таким образом, во вселенной произведения потерю ориентируемости в пространстве сопровождает разрушение однозначной упорядоченности во времени.

5 С актуальным в контексте фильма образом витка можно сопоставить и упоминание “восьмерки” (представляющей двойной виток) как числа, связанного со смертью героев: в таверне Розенкранц и Гильденстерн насчитывают в показанной актерами бойне 6 трупов, однако Актер тут же им возражает репликой, что на самом деле трупов 8, и в этом самый момент вдергивают двойников Розенкранца и Гильденстерна.

6 Подробнее вставное представление обсуждается в следующем разделе. 


\section{Композиция и топология}

Нетривиальные топологические характеристики проявляют себя также в необычном соотношении между категориями внутреннего и внешнего, которые в фильме не столько противопоставляются, сколько нейтрализуются, вновь актуализуя пространственные модели, основанные на односторонней поверхности. Случаи же иного рода (с сохранением противопоставления) носят в основном пародийный и комический характер, причем оппозиция внутреннего и внешнего имеет в них аномальный характер, включая взаимную мену этих состояний (“выворачивание наизнанку”).

Примером последнего может служить возникающий в начале фильма образ многослойного огромного бутерброда, который на привале в лесу (сцена незадолго до встречи с актерами) безуспешно пытается укусить Розенкранц: содержимое (еда) и содержащее (рот) оказались в соотношениях, обратных обычным. Во дворце Розенкранц и Гильденстерн, не зная где выход, пытаются идти за группой актеров, причем их бег за актерами по галереям здания показан с точки зрения извне; однако вслед за этим Розенкранц и Гильденстерн вдруг оказываются снаружи, смотря в ту же сторону, что и камера, причем их выход из здания не показан. Дело обстоит таким образом, как если бы пространство “вывернулось наизнанку”.

Игра указанными пространственными категориями организует и пространство произведения в целом. В фильме Розенкранц и Гильденстерн зашли во внутреннее пространство театрика, стали на сцене снаружи от занавеса, а потом вдруг камера показала, что они выпутываются изнутри занавеса во дворце. Причем непосредственно перед таким переходом герои услышали странные слабые голоса издалека, которые и “превратились” затем в раздающиеся во дворце голоса Офелии и бегущего за ней Гамлета, а монета единственный раз выпала не орлом, а решкой - как бы “вывернулась наизнанку”. Обратим внимание, что театральный занавес был в задней части сцены и отделял не пространство сцены от гипотетической публики снаружи, а внешнюю часть сцены от того невидимого, что было внутри и куда угодили Розенкранц и Гильденстерн, как бы пройдя сквозь занавес в театральное “зазеркалье” и фактически реализовав предложение Актера самим поучаствовать в действии, а также каламбур об 
“исключительно актерах" и “актерах включительно”. Иначе говоря, здесь Розенкранц и Гильденстерн превращаются в героев пьесы, представляющей вариацию “Гамлета" (добавим, что перед таким превращением в героев текста камера как раз показывает пачку старинной бумаги).

Однако утверждать, что они (как могло бы показаться, если ограничить анализ лишь указанным эпизодом) просто попали во внутреннее условное пространство из наружного реального, было бы неадекватным упрощением. Действительно, через некоторое время актеры прибывают во дворец, и Актер при встрече с Розенкранцем и Гильденстерном возмущенно пеняет тем, что они оставили актеров на дороге; Розенкранц в разговоре с Гамлетом также упоминает, что они с Гильденстерном обогнали актеров по пути в замок - стало быть, Розенкранц и Гильденстерн после встречи продолжили путь по дороге и попали во дворец своим ходом (причем эпизод с выпутыванием из занавеса имеет реалистическую мотивировку - занавес обрушил на героев не заметивший их Гамлет, который пробегал мимо, преследуя Офелию). Театр же, который актеры привозят некоторое время спустя в замок, остается внутри этого пространства дворца.

Таким образом, театральное пространство оказывается по отношению к пространству дворца и внутри и снаружи, т.е. фактически однозначное разделение и противопоставление этих состояний оказывается невозможным. Если представить себе художественное пространство в виде единого целого, то возникает топологически нетривиальная структура типа бутылки Клейна односторонней замкнутой поверхности, которая вкладывается в трехмерное пространство с самопересечениями. Другой подходящий здесь вариант пространственной модели - лист Мебиуса конечной толщины: переход через этот слой напрямую соответствует переходу в пространство дворца мгновенным перескоком, а по полоске (скручиванием которой получается лист Мебиуса) - попаданию героев во дворец обычным ходом.

Следует, однако, сделать оговорку. В отличие от "научно"фантастической литературы или кино, здесь речь не идет о необычных свойствах физического пространства как такового, поскольку переход в театральное пространство и перемещение по дороге имеют разный характер. В 1-м случае меняется статус действия и персонажей (повышается условность), во 2-м про- 
исходит обычное пространственное перемещение. Таким образом, упомянутая выше топологическая структура описывает не "реальное" пространство произведения само по себе, а представляет собой абстрактную модель, интегрирующую в себе реальное и условное пространства. Например, можно сказать, что Розенкранц и Гильденстерн после встречи с актерами прибыли во дворец по дороге, но уже как персонажи пьесы.

Невозможность однозначного разделения на условное и реальное (или на заранее фиксированные степени условности) присутствует, как сейчас мы увидим, и в сцене пантомимы во дворце. В “Гамлете" разыгранная бродячими актерами "Мышеловка" противопоставлена в качестве относительно условного пространства "реальному" пространству, в котором находятся действующие лица. Будем использовать краткие обозначения; тогда в пьесе Шекспира отравленному отцу Гамлета (королю 1) и его отравителю Клавдию (королю 2) соответствуют при разыгрывании пьесы актерами король 1а и отравитель Луциан (назовем его для простоты королем $2 \mathrm{a}$ - хотя, строго говоря, "Мышеловка" была прервана королем 2 до того, как корона досталась Луциану). Перед этим события пьесы были кратко показаны в пантомиме, в которой указанным лицам соответствовали король $1 \mathrm{~b}$ и отравитель (учитывая контекст пантомимы, его можно назвать королем $2 b)$.

В фильме порядок действия иной. Уже после того, как короли 1а и 2а (которых играют живые актеры) представляют на сцене “реальные" события с отравлением, пантомиму повторяют куклы в условном представлении с кукольными королями $1 \mathrm{~b}$ и $2 \mathrm{~b}$. За кукольным представлением наблюдает живой условный король 2а (чего не было в “Гамлете"), за представлением в целом наблюдает “реальный” король 2. Если в “Гамлете" пантомима была не самостоятельным целым, а всего лишь частью "Мышеловки", так что конструкция фактически была двойной (актеры - зрители, “Мышеловка" — “реальное” действие "Гамлета"), то в фильме эта конструкция оказывается тройной: куклы - актеры - зрители. Она является не механическим наращиванием условности по принципу “знак знака знака...” (“живой” король - актер - кукла), а привносит новое качество. Получается, что Актер и его труппа показывают на сцене уже не просто реальное преступление, совершенное ранее нынешним 
королем (как было в “Гамлете"), а отрывок из “Гамлета", включающий в себя показ “мышеловки”. Если в соответствующем фрагменте шекспировской пьесы король 2 видел перед собой только “мышеловку", то теперь он может видеть еще и собственную реакцию на нее. Это происходит из-за того, что король $2 \mathrm{a}$, увидя картину своего преступления в кукольной “мышлеловке", встает, прерывая представление, раньше "реального" короля 2. То есть не только король 2а следует за действиями короля 2 (тем, что представляет на сцене его преступление), но и король 2 , вставая позже короля $2 \mathrm{a}$, фактически следует за его действиями. В этом смысле в паре “король 2 - король $2 \mathrm{a}$ ” резко ослаблен контраст в мере условности между "реальными" персонажами и актерами, их представляющими. Это полностью согласуется с тем обстоятельством, что общий сюжет фиксирован (“Это написано”, как говорит Актер), так что ему на равных основаниях следуют и те и другие 7

"Мышеловка" в фильме является, с одной стороны, частью представляемого в нем варианта "Гамлета", а с другой — она сама содержит в миниатюре "Гамлет", включающий, как известно, в себя эту самую “мышеловку" как вставную пьесу. Последнее обстоятельство приводит к тому, что (в отличие от, скажем, сцены в таверне, где также показываются события "Гамлета", но которая сама по себе в "Гамлете" отсутствует) не только удваивается сюжет, но и структура в целом замыкается на себя. При этом вместо последовательности вложений, каждое из которых условнее предыдущего, получается единая конструкция с самопересечением, где однозначное разделение всей структуры на разные композиционные уровни или часть и целое невозможно. ${ }^{8}$

7 Можно было бы говорить о разной мере условности при механическом удвоении сюжета, если бы, например, король 2а и король 2 наблюдали разное число “мышеловок” со сценой убийства: первый только кукольную, а второй — и кукольную, и с живыми актерами. Однако именно этого и не происходит: король 2 входит в зал уже после того, как сцена убийства сыграна актерами. Так что и король 2 а и король 2 видят перед собой только по одной “мышеловке”, изображающей их преступление - это кукольный спектакль.

8 Напрашивается сопоставление со структурами, характерными для Борхеса (см. Левин 1981) и Набокова (см., например, Давыдов 1982). Однако такое сопоставление выходит за рамки нашей работы. 
Поэтому в том, что касается “мышеловки”, конструкция типа “текст в тексте” является в фильме принципиально иной, чем в “Гамлете” Шекспира, где происходило именно последовательное наращивание степени условности: "Так, например в "Гамлете" перед нами - не только “текст в тексте", но и “Гамлет" в "Гамлете": пьеса, разыгрываемая по инициативе Гамлета, повторяет в подчеркнуто условной манере [...] пьесу, сочиненную Шекспиром. Условность первой подчеркивает реальность второй” (Лотман 1981: 13-14). Здесь мы считаем необходимым внести коррективы в эти замечания Ю. М. Лотмана. Поскольку убийство Гамлета-старшего относится лишь к предыстории и в самом "Гамлете" не происходит, то его показ во вставной пьесе еще не означает композиционного удвоения той пьесы, частью которой является “мышеловка". Что же касается самой вставной пьесы, то хотя в "Гамлете" она благодаря пантомиме тоже удваивается, эта пантомима всего лишь повторяет в основных чертах действие обрамляющей ее пьесы (т.е. собственно “мышеловки”), но между “мышеловкой” и пантомимой нет прямых драматургических связей в самом действии. В противоположность этому, в фильме Стоппарда между пьесами разных уровней прямая драматургическая связь существует - реакция короля из обрамляющей пьесы включена во внутреннее представление. В результате структурное удвоение текстов разного уровня и приводит описанным выше образом к усложнению композиции в фильме по сравнению с "Гамлетом".

Сцена с повышенной степенью театральности возникает также в конце фильма. Актер устраивает представление, перевоплощаясь в английского короля, и приказывает повесить Розенкранца и Гильденстерна, дублируя уже разыгранное актерами представление в таверне, а также ту казнь, которая ждет героев в Англии. Обратим внимание, что в сцене казни за спинами героев просматривается дерево, и слышен щебет птиц - действие происходит в лесу, где Розенкранц и Гильденстерн встретили актеров. Таким образом, они гибнут втройне - как герои "Гамлета", персонажи спектакля в театральном “зазеркалье”, куда попадают после встречи с актерами, и “реальные” персонажи герои фильма. (Совмещение реального и условного в сцене казни находит структурный прототип в предшествующем рассказе Актера о том, как реальную казнь одного из своих сотрудников за 
кражу овцы он совместил с его ролью в спектакле, по ходу которого персонажа вешали.) 1-я казнь происходит в Англии (о чем в фильме, в соответствии с шекспировской пьесой, есть сообщение английского посла), 2-я — на корабле, 3-я - в лесу. Насильственная смерть оказывается тем инвариантом, который объединяет разные уровни реальности (в той мере, в какой их здесь вообще можно различить) в единое целое. 9

Доминирующая в фильме нераздельность реального и условного пародируется в эпизоде в таверне, где такое разделение происходит, но подчеркнуто комическим образом. Там актеры, изображающие Гамлета и Лаэрта, фехтуют воображаемыми рапирами, от которых, однако, слышится звук реальных ударов, причем показан видимый для зрителей в таверне помощник, который и производит этот звук, ударяя рапиры одна о другую. Этот эпизод содержит прозрачную отсылку к той же сцене в "Blow up" Антониони, о которой мы упоминали выше, - звукам ударов о воображаемый мяч при игре в теннис. Но если у Антониони воображаемое стремилось подменить собой реальность, то здесь реальное и условное демонстративно разделены - как если бы ударяющиеся рапиры были просто изъяты из рук соперников на сцене и перенесены в угол помощнику.

Если говорить о пространственной структуре в целом, то дело обстоит таким образом, что внутри театрального сундука находится мир “Гамлета"; заканчивается же фильм тем, что актеры собирают сундук (вместе с находившимся там ранее пространством "Гамлета") и отправляются дальше в странствие по дороге. Казалось бы, “мир” таким образом целиком находится внутри театра. Однако то обстоятельство, что актеры сами перед этим приняли активное участие в действии (вплоть до казни Розенкранца и Гильденстерна), находясь внутри театрика, который они же затем захлопнули, препятствует такому однозначному разделению на внутреннее и внешнее. (Об этом же говорят и другие описанные нами выше явления.) Произошло как бы выворачивание наизнанку в соответствии с высказыванием Актера “мы нечто обратное людям" и его ответом на вопрос, что же

9 Характерно, что в фильме в речи Актера опущена детализация разных видов смерти, присутствующая в пьесе (т.е. различия), и оставлены лишь его слова, подчеркивающие ее универсальность — "Deaths for all ages and occasions". 
они делают - “Обычные вещи, сэр, только наизнанку. Представляем на сцене то, что происходит вне ее. В чем есть некий род единства - если смотреть на всякий выход как на вход куда-то". Однако эти высказывания оказались существенно неполными, поскольку актеры в данном фильме не только представляют на сцене то, что происходит “в жизни”, но и наоборот (“наизнанку”), “в жизни” делают то, что представляют на сцене (о чем лукаво умолчал Актер) - например, вешают Розенкранца и Гильденстерна после того, как повесили их театральных двойников в пантомиме, разыгранной в таверне. Если актеры приобретают свойства "реальных" персонажей, то "реальные персонажи”, попав в находящееся внутри театрального сундука пространство, играют предназначенную им роль. Заметим, что в соответствующем высказывании Актера "Ну, одни считают, что мы для вас, другие, что вы для нас. Это две стороны одной монеты. Или одна сторона - двух, поскольку нас тут так много" фактически содержится намек на одностороннюю поверхность. Что же касается “выхода и входа", о которых говорил Актер, то из-за нетривиальной топологии “выход” оказывается иллюзорным и не отличимым от входа. В таком контексте знаменитое выражение “весь мир - театр” меняет свой статус и перестает быть метафорой, поскольку вместо двух разных объектов сравнения в фильме присутствует один единый, а “мир" и “театр" переходят друг в друга подобно тому, как вектор нормали меняет свою ориентацию при обходе по листу Мебиуса. Однако динамика переходов между условным и реальным оставляет неизменным инвариант - гибель героев, которой на односторонней поверхности не находится альтернативы.

\section{Статус героев и тип текста}

Как уже отмечалось нами выше, художественный мир произведения подразумевает цикличность, так что предстающее перед глазами зрителя или читателя следует понимать лишь как виток сюжета. Таким образом, имеет место превращение первоначально линейного исходного текста (“Гамлета") в цикл. Такая трансформация является типологически обратной по отношению к исторически известному превращению циклических текстов в 
линейные. Но если “очевидным результатом линейного развертывания текстов является появление персонажей - двойников" (Лотман 1973: 14), на которые распадается единый прежде образ, то в данном случае двойники возникают иначе. Персонажи, выступающие в "Гамлете" как независимые, сворачиваются (как мы старались показать это выше) у Стоппарда в единый объект, по отношению к которому они и оказываются двумя разными (причем не фиксированными - вспомним взаимные "превращения" между Розенкранцем и Гильденстерном) ипостасями - двойниками.

Особенностью циклических текстов является отсутствие категорий начала и конца. "Человеческая жизнь рассматривалась не как линейный отрезок, заключенный между рождением и смертью, а как непрестанно повторяющийся цикл” (Лотман 1973: 10). Однако эта особенность у Стоппарда усложнена и переосмыслена, а начало и конец выделены. Можно заметить, что содержанием цикла оказывается история героев от “рождения” до смерти. Герои, несмотря на все свои усилия, вспоминают в качестве первого события, оставшегося в памяти, отправку их посланником на выполнение неясной миссии. В таком контексте выкрикивание имен невидимым посланником может быть понято как "рождение” Розенкранца и Гильденстерна посредством наделения их именами и миссией. Это “рождение" является чисто функциональным - пока за ними не “послали”, у них не было никакой предыстории, они просто не существовали. И только став позднее персонажами не только фильма в целом, но и заключенной в нем пьесы на сюжет "Гамлета", они приобретают такую предысторию, оказываясь старыми друзьями принца. ${ }^{10}$ Что же касается содержания вышеупомянутой миссии Розенкранца и Гильденстерна, то она, как становится ясно из фильма (пьесы), заключается не в том, чтобы нечто выведать у Гамлета и помочь королю (как это было у Шекспира), а в том, чтобы оказаться в конце мертвыми. (Ср.: "Розенкранц. Они охотились за нами, а? С самого начала. Кто бы мог подумать, что мы такие важные

10 Так, во дворце Розенкранц восклицает: “Ничего не забыл — я всегда прекрасно помнил свое имя и твое тоже. О чем бы ни спрашивали - ответы были. Проблем не было - каждый знал, кто я такой”. К сожалению, эта определенность относится лишь ко времени, когда герои, как это аргументировано нами выше, не существовали. 
птицы? Гильденстерн. Но почему? Неужто все только ради этого? Неужто весь этот балаган сводится только к двум нашим маленьким смертям? (С тоской.) Кто мы такие? Актер. Вы Розенкранц и Гильденстерн. Этого достаточно”.) Иначе говоря, мир произведения порождает героев только для того, чтобы их убить.

Присущее мифологическому сознанию отождествление рождения и смерти здесь деавтоматизуется. Непреложность развития событий, ведущих к смерти героев (а циклические тексты рассказывают именно о правилах, а не эксцессах ${ }^{11}$ ) непрерывно сталкивается с мучительными, но безуспешными попытками героев избежать угрожающей им неясной опасности, а характерная для мифологических текстов цикличность - с упорным нежеланием индивидуума терять свою единственную жизнь. Вместо обычного циклического сюжета об умирании - возрождении получается циклический сюжет о невозможности избежать насильственной смерти.

\section{Локальная физика и геометрия в целом}

Топология листа Мебиуса (как и топологические свойства вообще) является нелокальной характеристикой, относящейся к миру в целом. Субъективно же герои пытаются передать этот глобальный аспект в терминах динамики: они ощущают, что попали в поле таинственных деперсонифицированных сил универсальных и дальнодействующих, и пытаются разобраться в их природе, определить, откуда же “дует ветер”, который может повлиять на их судьбу. При этом Гильденстерн предпочитает отвлеченные логико-философские рассуждения, а Розенкранц ставит физические опыты. Однако можно заметить, что в этих опытах каждый раз что-то не так оказывается как раз с соотношением глобального и локального - т.е. с наиболее значимым в данном контексте фактором.

Например, Розенкранц оказался близок к догадке, что при свободном падении (т.е. под действием тяготения - дальнодействующей и универсальной силы) тяжелые и легкие тела падают одинаково. Однако его опыт с бросанием деревянного

11 См. Лотман 1973: 11. 
шара и пера явно этому противоречит. Дело здесь в наличии воздуха (из-за чего падение нельзя считать свободным), т.е. локальной среды. В разговоре с Гильденстерном Розенкранц, заметивший, что его конструкция из бумаги вращается, если подуть на нее или пустить струю пара (непосредственное, локальное воздействие), заявляет, что никакого ветра нет, и тут же эта вертушка начинает вращаться. Розенкранц это объясняет сквозняком, т.е. внешней непосредственно действующей силой, но за этим объяснением следует визуальный намек на роль деперсонифицированной и “дальнодействующей” по отношению к судьбе героев силы, отправившей их в дорогу - показаны ставни, хлопающие подобно тому, как было в кадре с невидимым посланцем. Розенкранц также устраивает опыт с цепочкой бьющихся друг о друга подвешенных горшков с землей - здесь движение передается от одного края к другому на конечное расстояние. Однако такое “дальнодействие” в действительности получено в результате передачи импульса при непосредственном контакте горшков в моменты ударов, что является типично локальным эффектом. При увеличении же амплитуды размаха крайний горшок при соударении разбивается - соотношение между локальным (поведение отдельных предметов) и глобальным (движение цепочки в целом) остается для озадаченного героя в этом опыте столь же не проясненным, как и природа глобальных сил в его собственной судьбе. Что касается последнего обстоятельства, то локальные опыты являются здесь вообще бесполезными, поскольку не могут прояснить суть дела, которая связана со структурой мира как целого, включая его топологические свойства, и относится к совсем другому уровню абстракции.

\section{Заключение}

Таким образом, на основе односторонней поверхности как актуальной для произведения пространственной модели получили единое объяснение самые разные его особенности, в том числе и парадоксальные - то, что монета выпадает все время одной стороной, между Розенкранцем и Гильденстерном происходит путаница, между показанным и рассказанным есть видимое несо- 
ответствие (попадание во дворец, казнь в Англии и на корабле), физические опыты могут иметь отношение к надвигающейся на героев угрозе и т.д. При этом на более общем уровне при помощи указанной модели увязываются в единое целое структурные и тематические аспекты произведения - пространственная организация, соотношение реальности и условности, причинноследственные и сюжетные связи, проблема индивидуальности.

Художественное пространство - одна из важнейших категорий художественного текста, дающая “возможность пространственного моделирования понятий, которые сами по себе не имеют пространственной природы” (Лотман 1970: 266). В данном произведении мы, однако, сталкиваемся с более сложной и своеобразной ситуацией. Если, скажем, в случае с двойным попаданием героев во дворец категория пространства проявляет себя напрямую, то в таких эффектах как повторяющееся выпадение монеты одной стороной или путаница имен столь непосредственная связь отсутствует - актуальная для произведения пространственная структура типа односторонней поверхности проявляет себя в данном случае лишь как модель более высокого уровня абстракции. Вместо типичной для художественного текста ситуации “свойства пространства $\rightarrow$ моделируемые непространственные свойства" мы имеем в данном случае трехзвенную цепочку "непространственные свойства $\rightarrow$ свойства пространства $\rightarrow$ моделируемые непространственные свойства". Соответствующее пространство выступает при этом не как обычное физическое, а абстрактное (пространство альтернатив); отвечающая ему модель также отличается повышенной степенью абстрактности и, в отличие от реального “бытового" пространства, является неевклидовой. Тем самым область приложения понятий неевклидовой топологии в произведении оказывается шире, чем собственно хронотоп. Тот же факт, что неевклидова топология в произведении не ограничена какими-то частными проявлениями, а относится к основным свойствам мира как целого, придает ей “космологический” характер, заставляющий видеть здесь художественную аналогию концепциям теоретической физики 20-го и 21-го века. Речь идет не конкретно о листе Мебиуса (который в качестве гипотетической космологической модели вряд ли имеет какое-то отношение к реальной Вселенной), а о том общем обстоятельстве, что топология Все- 
ленной является значимой самостоятельной характеристикой и может существенно отличаться от евклидовой.

Почему же для воплощения нового варианта "Гамлета" потребовался концептуальный аппарат, оперирующий с понятиями, которые лежат за пределами круга бытовой реальности и связаны с таким уровнем абстракции, который стал актуальным только в науке 20-го века? Можно думать, что это связано с двумя основными причинами. В 20-м веке маленький человек претерпел (но и совершил) такое, ${ }^{12}$ что для описания соответствующего мира обычные наглядные “классические” средства оказались непригодны - так непригодными оказались локальные, мелкомасштабные способы познания действительности самими героями. Кроме того, актуальность именно топологических (т. е. глобальных) характеристик (причем ощутимых как раз благодаря их неевклидовости) связана с противопоставлением маленького человека и тотально контролирующей его глобальной системы у Стоппарда не социальной, а более глубинной экзистенциальной. Ее свойства предстают пугающе иррациональными, однако в действительности имеют собственные законы, определяющие ее “неевклидову” природу, по которым дело должно быть доведено до гибели героев. Для описания такой системы, которая не допускает альтернатив и неизменно приводит к гибели человека, односторонняя поверхность как раз и оказалась адекватным средством.

Проявление надличной и невидимой силы, объективный конечный смысл которой состоит в смерти “маленького человека", получает выражение и на интертекстуальном языке, которое также укладывается в рамки обсуждавшейся выше пространственной модели. Необычный пейзаж в начале фильма Стоппарда явственно напоминает аналогичный пейзаж в начале фильма Карне “Вечерние посетители". Текст, который сопровождает соответствующий видеоряд в фильме Карне, недвусмысленно сообщает о “посланцах дьявола" (у Стоппарда же герои мучительно вспоминают, что за ними “послали”). Как хорошо известно (и

12 Обратим внимание, что в отличие от шекспировского “Гамлета" Розенкранц и Гильденстерн узнают на корабле о содержании письма, но намереваются и дальше везти Гамлета на гибель. Однако расплачиваются они вовсе не за индивидуальный выбор - как говорит Актер, “Вы Розенкранц и Гильденстерн. Этого достаточно”. 
уже стало общим местом), произведение Стоппарда во многом отталкивается от пьесы "В ожидании Годо" Беккета, в названии которой просматривается наименование Бога. С учетом того, что какое-либо спасительное божественное вмешательство в судьбу героев Стоппарда отсутствует, бог и дьявол в таком контексте оказываются не противоположными сторонами одной медали, а разными ликами одной и той же надличной сущности на односторонней безальтернативно-гибельной для “маленького человека" поверхности.

\section{Литература}

Давыдов, Сергей С. 1982. “Тексты - матрешки” Владимира Набокова. München: Verlag Otto Sagner.

Левин, Ю. И. 1981. Повествовательная структура как генератор смысла: текст в тексте у Х. Л. Борхеса. Sign Systems Studies (Tpyды по знаковым системам) 14: 45-64.

Лотман, Юрий М. 1970. Структура художественного текста. Москва: Искусство.

- 1973. Происхождение сюжета в типологическом освещении. In: Лотман, Юрий М., Статьи по типологии культуры, вып. 2. Тарту: Тартуский гос. университет, 9-41.

- 1981. Текст в тексте. Sign Systems Studies (Tруды по знаковым системам) 14: 3-18.

Стоппард, Том 2000. Розенкрани и Гильденстерн мертвы. (Перевод И. Бродского.) Санкт-Петербург: Азбука.

Bloom, Harold (ed.) 2003. Tom Stoppard. New York: Chelsea House.

Brouwer, W. 1994. The image of the physicist in modern drama (Part 2). American Journal of Physics 62(3): 234-240.

Caris, John 1987. Foundation for a New Consciousness: An Essay on Art, Science, and Meditation. San Francisco: Westgate House.

Cobley, Evelyn 1984. Catastrophe theory in Tom Stoppard's "Professional Foul". Contemporary Literature 25(1): 53-65.

Fleming, John 2001. Stoppard's Theater: Finding Order Amid Chaos. Austin: University of Texas Press.

Jackson, Allyn 1995. Love and the second law of thermodynamics: Tom Stoppard's "Arcadia". Notices of the American Mathematical Society 42(11): 1284-1287.

Peterson, Ivar 2002. Drama in numbers. Science News 162: 392-393. 


\section{Väike inimene mitte-eukleidilises maailmas: kunstilisest ruumist Tom Stoppard'i filmis ja näidendis "Rosencrantz ja Guildenstern on surnud"}

Artiklis näidatakse, kuidas Tom Stoppardi teose erinevad aspektid ruumiline korrastatus, suhe reaalsuse ja sündmuste tingliku iseloomu vahel, põhjuslikud ja narratiivsed seosed, valiku ja isiksuse probleemid suhestuvad sellise ainukülgse ruumimudeliga nagu Möbiuse leht või Kleini pudel. Kunstiline ruum osutub mitte-orienteerituks, aeg selles voolab tsükliliselt. See võimaldab seletada Rosencrantzi ja Guildensterni nimede pidevat vahetusseminekut ja ka teisi paradoksaalseid käike süžees ja kompositsioonis. Möbiuse lehe mudel kehastab vaba valiku puudumist: maailmal ei ole teist palet ja ei ole võimalust pageda saatuse eest, mis on märgitud Stoppardi teose pealkirjas. Topoloogia olulisus seostub faktiga, et ohu kandjaks on maailm tervikuna. Lisaks viitab see ka tõsiasjale, et maailma struktuur on oma olemuselt mitte-eukleidiline ja seda ei ole võimalik mõista tavaelu vaatluste alusel või siis lähtuvalt Rosencrantzi poolt läbi viidud "ilmsetest" eksperimentidest. 